\title{
Deposition and assessment of thin dielectric films on photocathode substrate made of Kodial glass
}

\author{
V R KATTI and L M RANGARAJAN \\ Bhabha Atomic Research Centre, Trombay, Bombay 400085, India
}

\begin{abstract}
The development of $\mathrm{Cs}_{3} \mathrm{Sb}$ transmissive interference cathode technology needs processing of such photocathodes on thin dielectric films coated on glass substrates. Here the use of such films as light resonators is made for reducing the light losses due to reflection at the cathode surface. Consequently the sensitivity of the photocathode is enhanced. $\mathrm{TiO}_{2}$ and $\mathrm{SiO}$ films are chosen for their good optical properties with $\mathrm{Cs}_{3} \mathrm{Sb}$ photocathodes in interference photoemission. Deposition methods and instrumentation in assessing their properties are discussed.
\end{abstract}

Keywords. Interference photoemission; dielectric films; refractive index.

\section{Introduction}

Recent developments in electro-optical instrumentation with advanced technology in light sources, optical components and electronics have set the situation wherein the photocathode quantum efficiency places a limit on the total performance. Thus increasing the efficiency of the photocathode by optical interference phenomenon (Kossel et al 1969) is one of the methods. Thin films in conjunction with photocathode act as light resonators, due to the formation of standing wave within the films, facilitating large amount of light for photoemission. In the developmental techniques of transmissive interference photocathode ( $\mathrm{TIC})$ of $\mathrm{S}-9\left(\mathrm{Cs}_{3} \mathrm{Sb}\right)$ type, $\mathrm{TiO}_{2}$ and $\mathrm{SiO}$ thin films were selected for their matching optical properties such as high refractive index value, transmission and chemical compatibility with the photocathode (Katti 1979; Katti et al 1981). This paper describes the deposition methods of the above films, instrumentation techniques of measuring their optical properties and the application to interference photoemission.

\section{Experimental techniques}

The interference photoemission needs processing of photocathode in conjuction with non-absorbing thin dielectric films of known thickness, required refractive index (RI) value and transmittance in useful spectral region.

\subsection{Method of deposition}

Among various methods, reactive evaporation (Pulker et al 1976) of TiO (supplied by Balzers Ltd, W. Germany) in the ambient of oxygen is followed to assess its suitability to the special photodiodes employing Kodial glass to Kovar glass-to metal seals. 
Electron beam evaporation method is used. The $\mathrm{O}_{2}$ pressure, rate of evaporation and substrate temperature are controlled so as to get fully oxidized and non-absorbing films of high RI value. Thin $\mathrm{SiO}$ films are deposited by vacuum evaporation of $\mathrm{SiO}$ powder (supplied by Merk, W. Germany) in a high vacuum of $<1 \times 10^{-5}$ torr (Holland 1961). The evaporation source temperature in the range of $1250^{\circ} \mathrm{C}$ to $1350^{\circ} \mathrm{C}$ is maintained to prevent decomposition of $\mathrm{SiO}$ at elevated temperatures.

\subsection{Thickness measurement}

Thickness is the single most film parameter on which the end application of thin films for any device is greatly dependent. The phase condition for TIC is $n_{1} t_{1}+n_{2} t_{2}$ $=(\lambda / 2) \rightarrow 1$ where $n_{1}$ and $n_{2}$ are refractive indices and $t_{1}, t_{2}$ the thicknesses of the film and photocathode respectively. $\lambda$ is the wavelength of exciting radiation. The values of $n_{2}$ and $t_{2}$ for the $\mathrm{Cs}_{3} \mathrm{Sb}$ photocathode are $3 \cdot 2$ and $300 \AA$ approximately. The quartz crystal thickness monitor was employed for simultaneously monitoring the film thickness during growth as well as the evaporation rate. A sensitive AT cut quartz crystal with a natural frequency of $5 \mathrm{MHz}$ which was temperature-resistant and watercooled was used. The change in oscillation frequency $\Delta f$ is related to the thickness $t$ of the growing film by the equation $\Delta f=0.6 \times t \times d \rightarrow 2, d$ being the bulk density of the film material $\left(d=4 \cdot 3 \mathrm{~g} / \mathrm{cc}\right.$ for $\mathrm{TiO}_{2}$ and $2 \cdot 1 \mathrm{~g} / \mathrm{cc}$ for $\left.\mathrm{SiO}\right)$.

The thickness by the quartz crystal was monitored for different films by measuring the exact geometrical thickness using Tolansky's interferometric method. The experimental set-up is shown in figure 1. An interference filter transmitting the

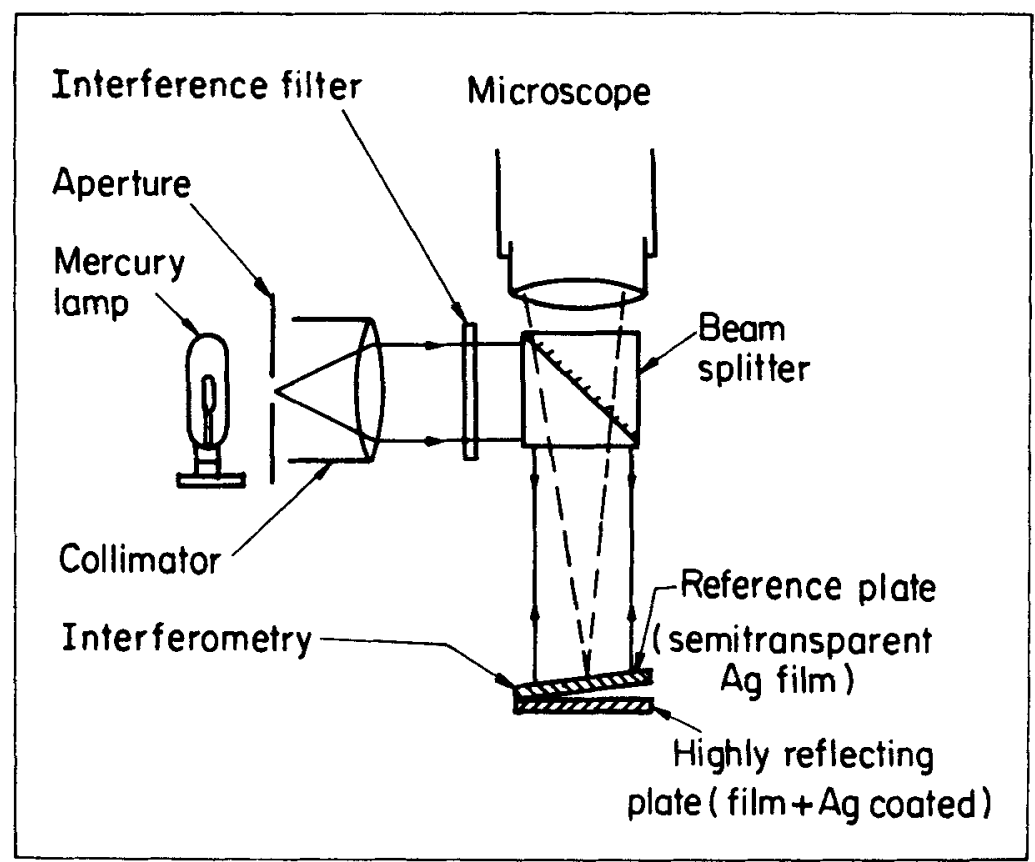

Figure 1. Schematic diagram for multiple beam Fizeau fringe interferometry. 
wavelength $(\lambda=5460 \AA)$ in front of a $\mathrm{Hg}$-discharge lamp gives monochromatic light. The film thickness is given by the equation

$$
t=(\lambda / 2)(\Delta / d) \rightarrow 3
$$

where $\Delta$ is the fringe shift and $d$ the fringe width. Since surface planacity of the glass plate is important, silver or aluminium step-coatings are given for high contrast in the array of the fringes. The calibration curves relating both methods of thickness measurement for $\mathrm{TiO}_{2}$ and $\mathrm{SiO}$ films are shown in figure 2 .

\subsection{Refractive index and transmission measurements}

In interference photoemission, a knowledge of RI of dielectric films is necessary for selecting suitable films for the photocathode to satisfy the amplitude condition. Measurement of Brewster's angle by Able's method is used here. The reflection at coated and uncoated substrate is measured using a plane-polarized, monochromatic light at different angles of incidence. The RI of the film is given by the equation $n=\tan \theta$ $\rightarrow 4$ for equal reflection from coated and uncoated region, $\theta$ being the angle of incidence (Brewster's angle). The photomultiplier tube and M4Q III spectrophotometer are used. $\theta$ is determined graphically (figure 3). The spectral transmittance of the film is measured by using a quartz prism monochromator (M 4 Q III-Carl Zeiss) and is shown in figure 4. These data are essential for the TIC technology and interpretation of the results.

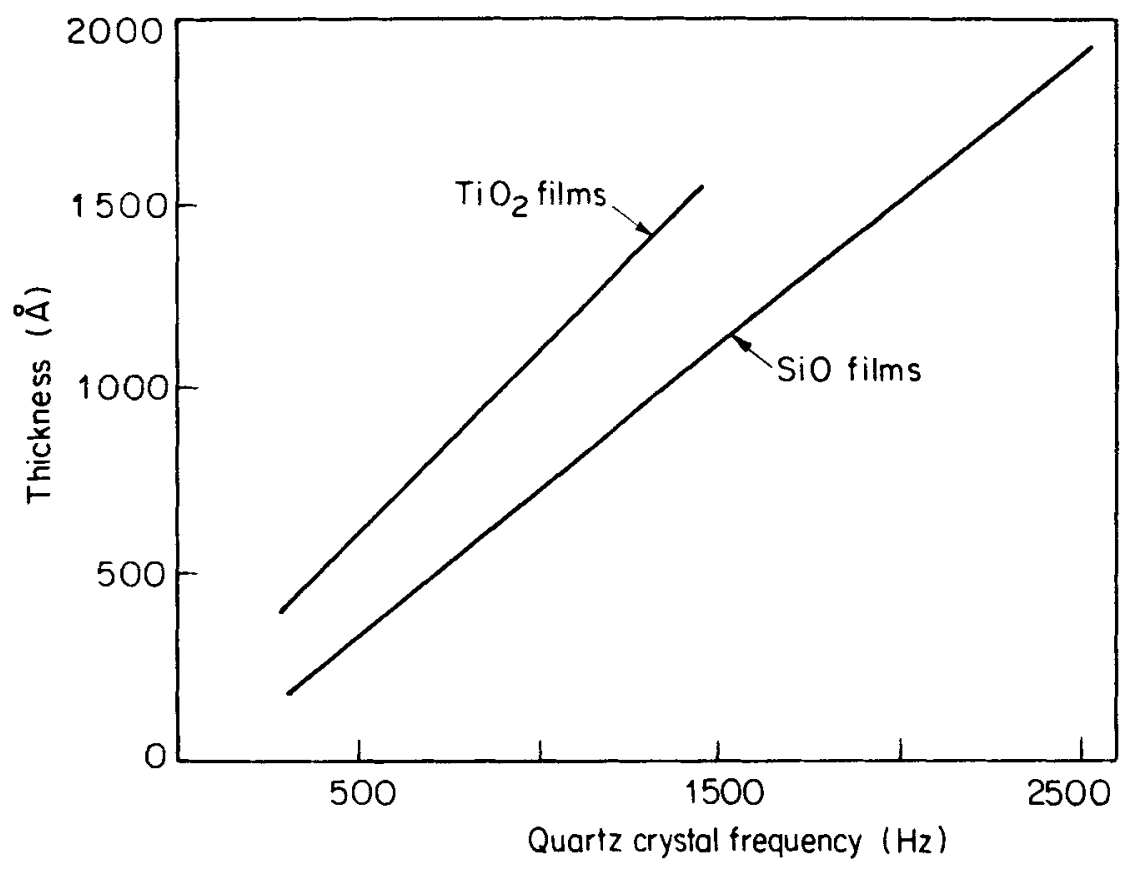

Figure 2. Relation between quartz crystal monitor and actual thickness for dielectric thin films. 


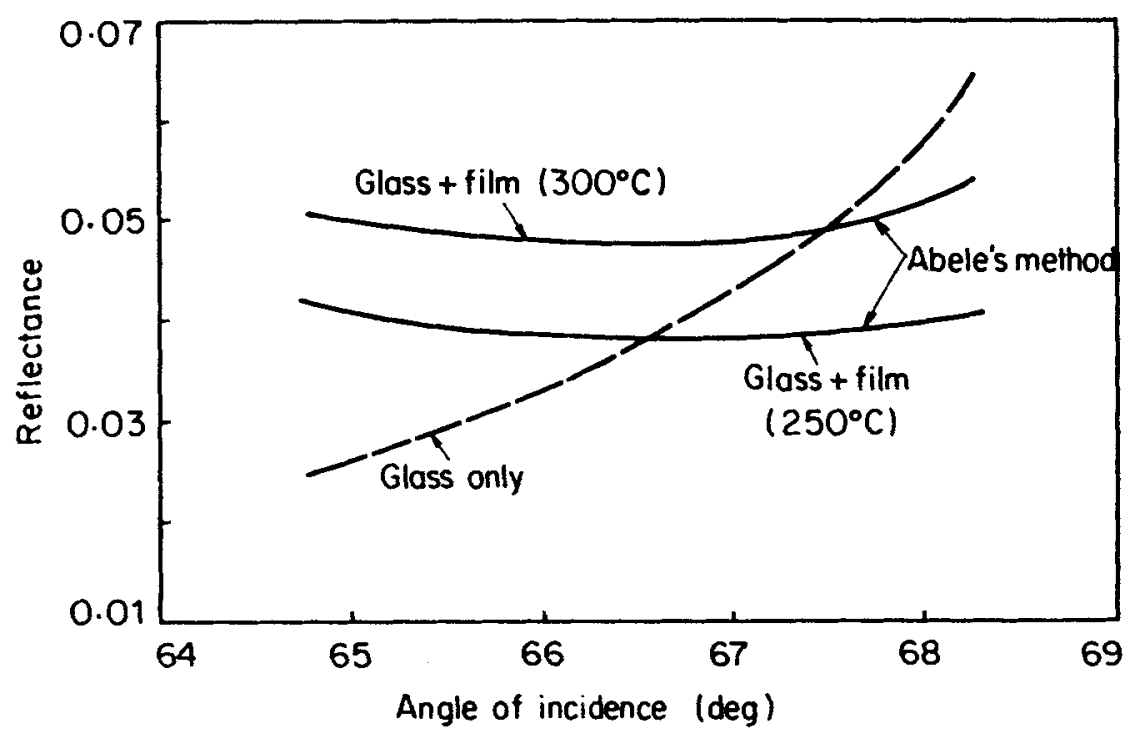

Figure 3. RI measurement for $\mathrm{TiO}_{2}$ films made by reactive evaporation method at different substrate temperatures.

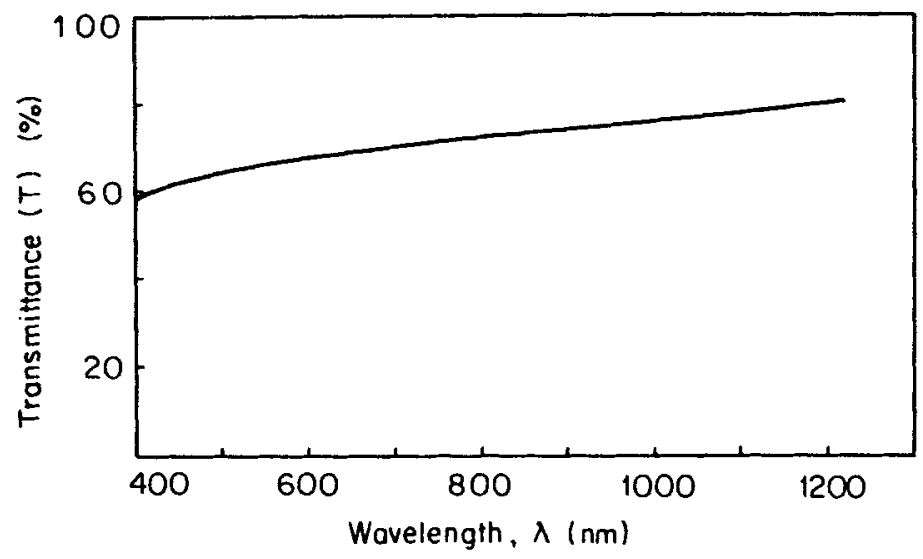

Figure 4. Spectral transmittance of $\mathrm{TiO}_{2}$ film (scanned by M4 Q III monochromator).

The photodiode tube assembly is shown in figure 5. Films of required thickness are deposited on Kodial glass plate sealed to metallic Kovar eyelets by glass-to-metal seals. These components are used as photocathode substrates in image converter and image intensifier tubes.

\section{Results and Discussion}

Film properties such as RI and transmittance depend on the conditions of deposition. In order to process $\mathrm{TiO}_{2}$ films by reactive evaporation of $\mathrm{TiO}$ material, oxygen pressure is 
To $C_{s}$ generator

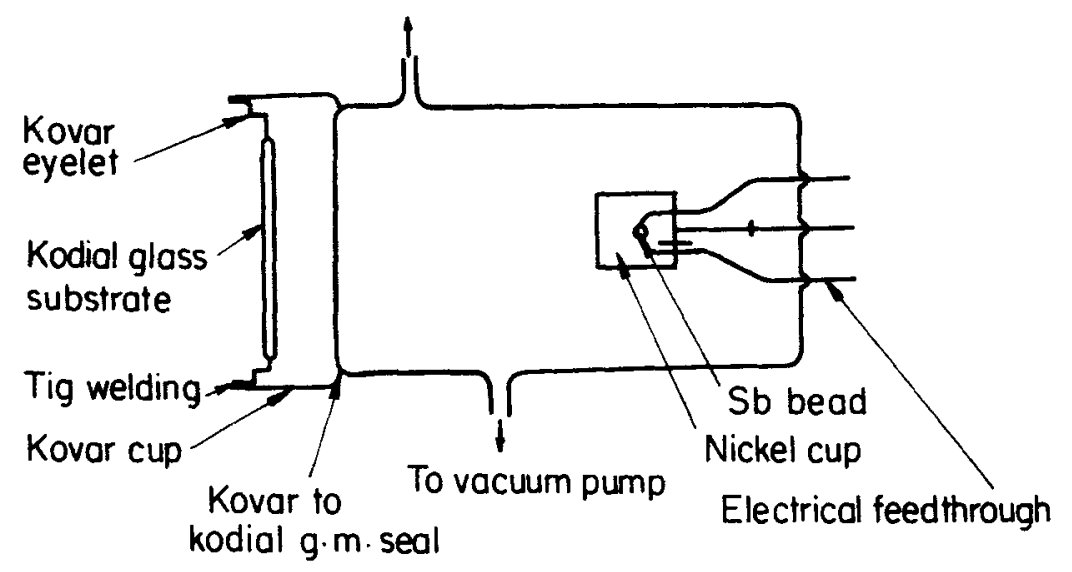

(a)

Aluminium ring film

for electrical contact

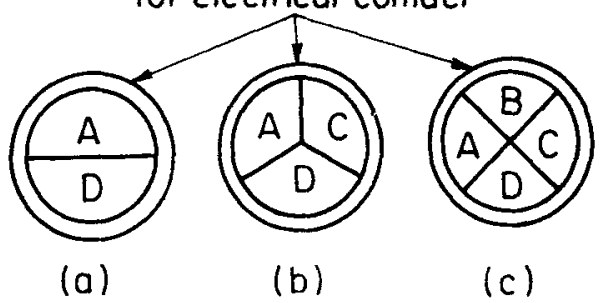

$A=$ Tuning at $560 \mathrm{~nm}, B=$ Tuning at $600 \mathrm{~nm}$

$C=$ Tuning at $620 \mathrm{~nm}, D=$ Uncoated region

(b)

Figure 5. (a) Experimental photodiode tube and (b) substrate configurations.

kept at $1.5 \times 10^{-4}$ torr so that the films are fully oxidized and non-absorbing (Ritter 1968). The rate of evaporation is $7 \AA / \mathrm{sec}$ for films processed at two different substrate temperatures of $250^{\circ} \mathrm{C}$ and $300^{\circ} \mathrm{C}$; the RI values for $\mathrm{TiO}_{2}$ are 2.42 and 2.30 respectively at $300^{\circ} \mathrm{C}$ and $250^{\circ} \mathrm{C}$ (figure 3). This variation in $\mathrm{RI}$ is due to crystal imperfection as established by Bright Field (BF) and Selected Area Diffraction (SAD) electron micrographs. The films are polycrystalline, tending towards anatase. However, direct oxidation of Ti films in air at $450^{\circ} \mathrm{C}$ yields $\mathrm{TiO}_{2}$ of $\mathrm{Rl}$ value $2 \cdot 6$, which is required for TIC. We could not pursue this method further because of its unsuitability to Kodial glass substrates with glass to metal seals. Thin films of $\mathrm{SiO}$ are deposited in a vacuum of less than $1 \times 10^{-5}$ torr, the substrate temperature being $250^{\circ} \mathrm{C}$. The evaporation source 

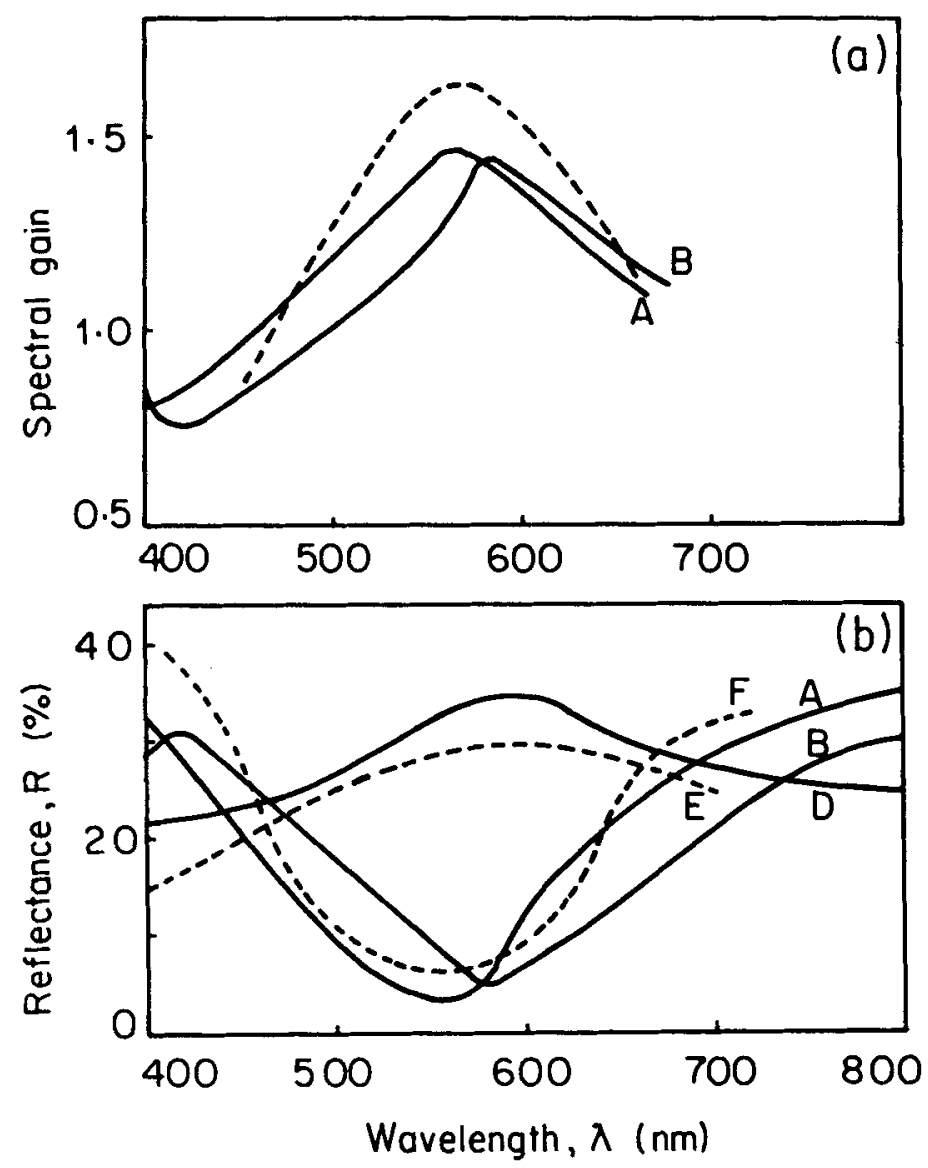

Figure 6. (a) Spectral gain and (b) reflectance characteristics for $\mathrm{TiO}_{2}-\mathrm{TIC}$ samples: A. $\mathrm{TiO}_{2}-\mathrm{TIC}$ at $560 \mathrm{~nm}$; B. $\mathrm{TiO}_{2}-\mathrm{TIC}$ at $600 \mathrm{~nm}$; D. S-9 Photocathode; E. Computed (R) for S-9; F. Computed (R) for $\mathrm{TiO}_{2}-\mathrm{TIC}$ at $560 \mathrm{~nm}$.

temperature was kept within $1350^{\circ} \mathrm{C}$ because the films above this temperature are likely to contain $\mathrm{Si}$ and $\mathrm{SiO}_{2}$. SiO films of RI value 1.82 can be obtained with the above conditions in addition to the rate of evaporation of $12 \mathrm{~A} / \mathrm{sec}$.

The quartz crystal thickness monitor and Tolansky's interferometric instrument for the assessment of thickness of the films are complementary to each other. RI measurement for these optical films by Able's method is quite simple; however the use of photomultiplier tube spectrometer with fine angular graduations and the optical arrangement of lenses, slits and monochromator increase the accuracy of measuring techniques. The accuracy obtained in RI value is \pm 0.05 , fairly sufficient for the TIC development work.

The enhancement in photocathode sensitivity by interference mode is achieved to the tune of 1.45 for $\mathrm{TiO}_{2}-\mathrm{TIC}$ (Rangarajan and Katti 1978) in the tuned spectral region as shown in figure 6. The agreement obtained between experimental results and theoretical computations shows the right optimization of the deposition parameters of these films as well as the reliability of the instrumentation in assessing their properties. 
A gain of 1.25 in photocathode sensitivity in tuned spectral region is recorded for $\mathrm{SiO}-\mathrm{TIC}$.

\section{Conclusions}

$\mathrm{TiO}_{2}$ films deposited at $300^{\circ} \mathrm{C}$ substrate temperature by reactive evaporation of $\mathrm{TiO}$ in $\mathrm{O}_{2}$ pressure of $1.5 \times 10^{-4}$ torr are polycrystalline, tending towards anatase, of RI value 2.42 and nonabsorbing, in the useful spectral region. SiO films of $\mathrm{RI}=1.8$ are obtained by evaporation of $\mathrm{SiO}$ in a vacuum $<1.0 \times 10^{-5}$ torr. The enhancement in photocathode sensitivity is 1.45 times over the normal mode for $\mathrm{TiO}_{2}-\mathrm{TIC}$ in the tuned spectral region.

\section{Acknowledgements}

We thank S S Ramamurthi and S N Seshadri for their encouragement.

\section{References}

Holland L 1961 Vacuum deposition of thin films (London: Chapman \& Hall)

Katti V R $1979 \mathrm{~A}$ study of $\mathrm{Cs}_{3} \mathrm{Sb}$ transmissive interference photocathode, M.Sc. thesis, University of Bombay Katti V R, Rangarajan L M and Bhide G K 1981 Vacuum 30497

Kossel D, Deutscher K and Hirschberg K 1969 Physics of thin films (eds) G Hass and R E Thun (London: Academic Press) Vol. 5, 1-45

Pulker H K, Paesold G and Ritter E 1976 Appl. Opt. 152986

Rangarajan L M and Katti V R 1978 Proceedings of Symposium on Electron Devices, Pilani, CEERI, India, p. 3-31

Ritter E 1968 Blazers High Vacuum Information 16385 